IJPPM

58,3

274

Received September 2008 Accepted October 2008

\section{REFLECTIVE PRACTICE Six Sigma vs TQM: some perspectives from leading practitioners and academics}

\author{
Jiju Antony \\ Strathclyde Institute for Operations Management (SIOM), \\ University of Strathclyde, Glasgow, UK
}

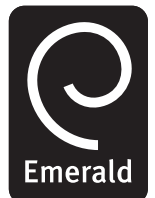

International Journal of Productivity and Performance Management Vol. 58 No. 3, 2009 pp. $274-279$ (C) Emerald Group Publishing Limited $1741-0401$

DOI $10.1108 / 17410400910938869$

\begin{abstract}
Purpose - This paper aims to present the fundamental and critical differences between two of the most powerful philosophies of modern quality management.

Design/methodology/approach - The approach taken was to form a panel of leading academics and practitioners who are familiar with both the Six Sigma and Total Quality Management (TQM) topics.

Findings - The findings of the panel discussion were quite stimulating in the sense that the paper demystifies the myth that Six Sigma is an old wine in a new bottle or that it is another hot topic or flavour of the month. The author believes that this will be extremely useful to many practitioners and researchers in these fields.

Research limitations/implications - The viewpoints expressed here are based on many practitioners and academics in a few countries such as the USA, Singapore, India, the UK and Korea. It is essential to collect data on this topic from a number of leading researchers and practitioners in the field from other countries and to set out a research agenda in the future.

Originality/value - The paper provides an excellent resource for those people who are currently carrying out research in Six Sigma. Moreover, it is equally useful to practitioners and academics to understand the critical differences between these two powerful approaches to quality management.
\end{abstract}

Keywords Quality, Six sigma, Management strategy, Business excellence, Total quality management Paper type Viewpoint

Six Sigma as a powerful management strategy has evolved from being exclusively about the original goal of a target of less than 4 failures or defects or errors per million opportunities, to encompass a broad range of approaches for incorporating quality into products and services from the early design and development stages and throughout their lifetimes. Many companies world-wide (manufacturing companies, service oriented companies, small and medium sized enterprises, etc.) have implemented Six Sigma and achieved remarkable improvements in their market share, customer satisfaction, product reliability, service quality etc. with impressive financial savings. TQM is a broad management philosophy embracing all activities through which the needs and expectations of the customer and the objectives of the organisation are satisfied in the most efficient and cost effective way by maximising the potential of all employees in a continuing drive for improvement. Many academics and practitioners of TQM strongly argue that there are no critical differences between these two approaches to quality management. This paper illustrates the point that TQM and Six 
Sigma are not the same. Although there are many commonalities between these two philosophies, there are some real and critical differences between them. A panel of academic experts and practitioners were chosen to discuss the topic "How would you compare Six Sigma with TQM?”

The people who have participated in this panel discussion include the leading academics in the field, Six Sigma pioneers and practitioners from 5 countries. The panelists who have participated in this study will explain the fundamental and critical differences between these two powerful approaches to quality.

\section{Dr Rick L. Edgeman, Professor and Chair, Department of Statistics, University of Idaho, USA}

I would say that SIX SIGMA is: "A highly structured, information-driven strategy for product, system and enterprise innovation and design". In contrast I would say that TQM "seeks to satisfy customer needs continuously by providing what they desire at the lowest possible cost as a result of involving a critical mass of the organization's human resource."

Both can be effective and it is at times difficult for me to say "THIS is Six Sigma but THAT is TQM". However, Six Sigma's strong ALGORITHMIC approach...e.g.... it provides a ROADMAP for getting things done is a very important aspect separating Six Sigma from TQM. A second distinguishing characteristic is the SUPERIOR ABILITY of Six Sigma to logically integrate/coordinate use of various tools/techniques/strategies that are commonly used in isolation as it progresses through DMAIC or DMADV applications. ADDITIONALLY, the algorithms are sufficiently flexible as to allow - even encourage - borrowing of useful methods from other fields.

\section{Dr Matthew Hu, Vice President of Robust Sigma Technology, USA Facts:}

- TQM implementation had limited success. Low probability of success deterred many organizations from trying TQM. Instead, many organizations opted for ISO 9000. ISO 9000 promises not world-class performance levels, but "standard" performance. TQM offered a mushy set of philosophical guidelines and no way to prove that one had accomplished their quality goals.

- Six Sigma has demonstrated success by clearly providing a roadmap and process for the business management (not only quality).

It may be fair to compare Six Sigma with TQM based on the following criteria:

- Leadership involvement.

- Business priorities alignment with focus on customer requirements and bottom line financial results.

- Opportunity for everyone's involvement across the company to join the game.

- Data driven decision-making and problem solving based on the project execution.

- Flexibility to fit any type of business, e.g. transaction or manufacturing issues.

\section{Six Sigma vs}

TQM

275 
IJPPM

58,3
Six Sigma is proven to be a better business strategy than TQM for the following reasons:

- It gets the top leadership involved in Quality and demands their personal time and commitment. TQM was run by "Quality techies".

- Six Sigma ties in projects with big business priorities aligned with customer's requirements and also with bottom line financial results (and that is why the top bosses love it!).

- Six Sigma makes it easier for organizations to succeed by providing a clear roadmap to implementation and deployment. Organizations are more willing to invest the effort if they know that a pot of gold awaits them at the end.

\section{Dr Roger Hoerl, GE Global Research, USA}

Six Sigma borrows much from TQM: a process viewpoint, a focus on variation reduction, and the use of statistical methods, to name a few. However, Six Sigma also strives to address several of the shortcomings of TQM, such as lack of a bottom-line orientation, lack of dedicated resources, an informal and uncoordinated project selection process, and use of "whoever is available" to conduct projects. The addition of a bottom-line orientation, dedicated resources that represent the organization's top talent, and coordinated projects selected by management that deliver results in three to four months have significantly enhanced Six Sigma relative to TQM. It is unlikely that anyone will go back to TQM once they have seen Six Sigma in action.

\section{Dr Tom Pyzdek, Pyzdek Consulting, USA}

The primary difference, in a word, is management. Unlike TQM, Six Sigma was not developed by techies who only dabbled in management and therefore produced only broad guidelines for management to follow. Six Sigma was created by some of America's most gifted CEO's, people like Motorola's Bob Galvin, AlliedSignal's Larry Bossidy and GE's Jack Welch. These people had a single goal in mind: making their businesses as successful as possible. Once they were convinced that the tools and techniques of the quality profession could help them do this, they developed a framework to make it happen: Six Sigma. More information can be obtained from the following link: www.qualitydigest.com/feb01/html/sixsigma.html

\section{Professor T.N. Goh, National University of Singapore, Singapore}

Six Sigma provides a clear roadmap for improvement and is meant to be rigorous in personnel development and implementation. Statistical thinking is the cornerstone of Six Sigma. Six Sigma does not depend on the TQM framework but it empowers an organization implementing TQM.

\section{Professor Amitava Mitra, University of Auburn, USA}

As a philosophy, there are similarities between Six Sigma and TQM. There are three major themes in TQM, namely the customer, process, and employees. At the core of TQM are the company vision and mission and management commitment. This core attempts to integrate the components of customer, process, and people. 
Six Sigma utilizes these foundations as well. As discussed previously, senior management commitment is essential to the success of Six Sigma. Further, customer focus is firmly integrated into the Six Sigma approach. The prioritizing of problems to tackle is strongly impacted by customer needs. Process improvement (manufacturing, business processes, service operations) is the backbone of Six Sigma. Recommended changes in processes are evaluated in terms of performance metrics that can be measured (say, for example, proportion nonconforming). Additionally, through the usage of cross-functional teams, Six Sigma has a common theme of empowerment as does TQM.

While the above points demonstrate similarities between Six Sigma and TQM, there are some differences in terms of the approach and emphases. First, there is a more structural approach in Six Sigma. The Define (D), Measure (A), Analyze (A), Improve (I), and Control (C) phases solidify this point. Using such a structural approach assists the problem-solving process and in some sense is helpful in setting up milestones to monitor progress on the project. By specifying methodologies and tools for each of these phases, it assures transition from one phase to the next and thereby timely completion.

While continuous improvement is a theme in both Six Sigma and TQM, in TQM there was not necessarily an outcome measure, with financial implications, related to each project undertaken. This could have been a reason for the decaying degree of support from top management.

Usually, in Six Sigma projects, while a team-leader is identified (say, a Black Belt), there is also a Champion, who serves as a major link for top management. With such representation from senior management, that was not necessarily the case in TQM, the chances of commitment from top management, project completion, and implementation are enhanced.

\section{Professor Sung Park, National Seoul University, South Korea}

I believe that Six Sigma is more process-oriented, project-oriented and profit-oriented than TQM. Six Sigma is clearer than TQM in many aspects for quality innovation. Six Sigma fits in to the knowledge-based information society than TQM. Recently, in Korea, more companies adopt Six Sigma than TQM for their management strategy.

\section{Professor S.N. Neogy, Indian Statistical Institute, India}

The Six Sigma vision or approach seems to cover a wider front in tune with the TQM approach as presented in the existing literature. Six Sigma has succeeded in presenting a more integrated package or product with required statistical and other available non-statistical tools. Nevertheless, the package is quite large as ever! It is not the same story as TQM being told once again in a different format. The goal is to achieve Six Sigma product, Six Sigma services and Six Sigma suppliers. On the organizational side, new graphic and easy to visualize roles like champions, black and green belts are introduced for driving home an aggressive implementation approach to combat the ever present resistance to change or even to the current new Six Sigma concept. A major deficiency of TQM approach is the absence of real project for driving the improvement vehicle.
Six Sigma vs
TQM

277 
IJPPM

58,3

278

\section{Professor Jiju Antony, Director, Centre for Research in Six Sigma and Process Excellence (CRISSPE), University of Strathclyde, Scotland, UK}

In my personal opinion, Six Sigma builds on many of the aspects of previous continuous improvement initiatives, in particular TQM. TQM often lacked a deployment process and the associated managerial and leadership components needed to drive fundamental change in an organization.

Some of the traits of TQM that are copied in Six Sigma are:

- a customer-centric approach;

- a process view of work;

- a continuous improvement mindset;

- improving all aspects and functions of the organization;

- data-based decision making; and

- the use of statistical tools on a broad basis.

Six Sigma has both a "deployment" aspect and a "methods and tools" aspect. Most of the Six Sigma methods and tools were applied in TQM initiatives, so they are not really new. It is the systematic and disciplined integration of powerful problem solving tools and techniques into the DMAIC framework has been the most important addition of Six Sigma. Such an integrated approach was sorely missing in most TQM implementations, where practitioners often floundered trying to wade through a diverse set of statistical and problem solving tools.

Six Sigma provides the needed leadership, organizational culture and infrastructure to enable the methods and tools to be successfully deployed across the business. This aspect was totally missing in TQM philosophy. There is no clear infrastructure for the deployment of TQM in any business. I also believe it would take much more time to realize any benefits from the implementation of TQM as opposed to Six Sigma. Fortunately, three major success factors in Six Sigma - committed leadership, top talent and supporting infrastructure - enables Six Sigma to deal with these deficiencies.

\section{Further reading}

Dale, B.G. (Ed.) (1994), Managing Quality, Blackwell Publishers, Oxford.

Hoerl, R. (2004), "One perspective on the future of Six Sigma”, International Journal of Six Sigma and Competitive Advantage, Vol. 1 No. 1, pp. 112-19.

Snee, R. (2004), "Six Sigma: the evolution of 100 years of business improvement methodology", International Journal of Six Sigma and Competitive Advantage, Vol. 1 No. 1 , pp. 4-20.

\section{About the author}

Jiju Antony, Director of the Centre for Research in Six Sigma and Process Improvement (CRISSPE) within SIOM, in his ten years of research career, has published more than 150 refereed papers and five textbooks in the area of Design of Experiments, Taguchi Methods, Six Sigma, Total Quality Management and Statistical Process Control. Professor worked as a maintenance engineer for two years, Quality Manager for two years and a Quality Management and Six Sigma consultant and trainer for over eight years. The clients included Nokia (Oulu), Rolls-Royce (Derby), Parker Pen (Brighton), Siemens (Newcastle), Bosch 
(Cardiff), Procter \& Gamble (Hampshire), Triplex Components (Midlands), etc. He has been invited several times as a keynote speaker to national conferences on Six Sigma in China, South Africa, The Netherlands, Dubai, Greece, New Zealand, South Africa and Poland. He has also chaired the First and Second International Conferences on Six Sigma and First European Research Conference on Lean Six Sigma. He has been recently invited to the Scottish Parliament to deliver a talk on "Process and Quality Thinking for creating World Class Business Leaders in Scotland by 2020". He has been considered for "Who's Who in the World" based on his recent contributions to the field of Quality Management and Six Sigma. Jiju Antony can be contacted at: jiju.antony@strath.ac.uk

\section{Six Sigma vs TQM}

279

To purchase reprints of this article please e-mail: reprints@emeraldinsight.com Or visit our web site for further details: www.emeraldinsight.com/reprints 